\title{
APRESENTAÇÃO
}

\section{CONTRASTE ENTRE SEXOS, CONTRASTE ENTRE MULHERES}

Mudanças radicais no estatuto da mulher marcaram as últimas décadas. As mais notáveis foram o incremento da escolaridade, a significativa ampliação da participação no mercado de trabalho e a consequente implosão do modelo de família com provedor único. A constância e a intensidade desses processos sinalizam uma estrada sem volta.

As mulheres brasileiras vêm avançando de forma significativa no mercado de trabalho: apenas na década passada ocorreu um incremento de $24 \%$ na atividade feminina. O perfil da trabalhadora também se alterou; a maioria deixou de ser solteira e sem filhos e passou a ser casada e mãe.

No entanto, esse percurso é acompanhado por notas estridentes: persistem desigualdades na remuneração, no tipo de ocupação e no uso do tempo de homens e mulheres.

As mulheres auferem em média 70\% dos salários masculinos, disparidade de rendimentos que aumenta em função dos anos de estudo num efeito perverso da escolaridade. Precariedade e vulnerabilidade no emprego são maiores no grupo das mulheres que no dos homens, com peso significativo do trabalho doméstico remunerado. Este representa em torno de $17 \%$ da força de trabalho feminina.

A distribuição entre os sexos do tempo gasto em afazeres domésticos permaneceu intocada na última década. As mulheres continuam a ser as principais responsáveis pelos cuidados com a casa, com as crianças e com os idosos e os doentes. Dedicam 25 horas por semana aos 
afazeres domésticos, um pouco menos que as 27 horas gastas em 2002; já a situação dos homens não se alterou: eles continuam despendendo 10 horas como faziam anteriormente.

Persiste uma desvalorização fundamental de todos os tipos de trabalho realizados pelas mulheres no âmbito doméstico.

Como adverte Helena Hirata, ${ }^{1}$ enquanto a conciliação entre vida profissional e vida familiar, trabalho assalariado e trabalho doméstico for pertinente apenas para as mulheres, permanecerá intacta a hierarquia que confere superioridade ao masculino sobre o feminino.

Trabalho e Gênero, sem pretender esgotar as inúmeras dimensões da atividade feminina, busca fornecer subsídios para o debate a respeito da participação da mulher no mercado de trabalho formal e informal, do trabalho doméstico remunerado ou não e dos dilemas da articulação entre família e trabalho.

Estão reunidas neste dossiê contribuições ao seminário Trabalhos de mulher - desafios para a pesquisa no século XXI, realizado em maio de 2013. Primeiro de um ciclo cujo objetivo é realizar um inventário da produção acadêmica sobre o tema, sinalizando avanços e lacunas do conhecimento, esse evento visou retomar a tradição da Fundação Carlos Chagas de promover seminários de avaliação do campo dos estudos de gênero.

Magda de Almeida Neves fornece um panorama sobre os estudos relativos à mulher no mercado de trabalho no Brasil, com atenção especial à contribuição pioneira de Cristina Bruschini e à linha de investigação sobre divisão sexual do trabalho representada notadamente por Daniele Kergoat e Elisabeth de Souza Lobo. Examina a trajetória do tema desde as análises que articulam vida profissional e família, esfera produtiva e esfera reprodutiva até os estudos mais recentes sobre globalização e reestruturação produtiva, enfatizando seu impacto para a reformulação da Sociologia do Trabalho.

Jurema Gorski Brites faz um balanço dos eixos temáticos que têm norteado a literatura sobre trabalho doméstico remunerado; recrutamento nos segmentos sociais mais vulneráveis economicamente e mais desvalorizados em razão de raça ou etnia, desproteção legal e fragilidade de organização sindical. Indica que essa relação de servidão, apesar de sua magnitude no contexto latino-americano, só recentemente começou a merecer a atenção dos estudiosos e que muitos de seus aspectos permanecem inexplorados. Examina também os possíveis impactos das recentes alterações na legislação trabalhista.

Angela Maria Carneiro Araújo e Maria Rosa Lombardi, em análise da evolução do trabalho informal segundo sexo e raça no Brasil da última década, constatam as heterogeneidades que marcam o setor e as desiguais oportunidades de mulheres e negros em relação a homens e Margaret; HIRATA, Helena (Org.). As novas fronteiras da desigualdade: homens e mulheres no mercado de trabalho. São Paulo: Editora Senac, 2003. 
brancos, comprovando a validade da clássica pirâmide de rendimentos em que homens brancos estão no topo, seguidos dos homens negros, das mulheres brancas e, por último, das mulheres negras, objeto de dupla discriminação.

A posição de classe dos homens é indiferente, quase não afeta o tempo consumido em afazeres domésticos, mas a renda é para as mulheres um fator de diferenciação significativo. Segundo a análise de Bila Sorj sobre os dispositivos de cuidado no Brasil, o cruzamento de dois sistemas de hierarquização, de gênero e de classe social, é crucial para entender como se configuram diferentes e desiguais experiências sociais do cuidado.

Os artigos do dossiê, além de contrastarem o universo do trabalho masculino e feminino, ressaltando desigualdades de gênero, evidenciam importantes desigualdades entre mulheres: uma progressão da atividade feminina marcada pela bipolarização das ocupações entre acesso a profissões de prestígio e cargos de comando, de um lado, e concentração em empregos precários e mal pagos, de outro; a dupla discriminação que grava as mulheres negras; a posição de classe moldando variadas experiências domésticas, desde o lugar de patroa ou empregada até diferenças no acesso a recursos e a equipamentos sociais.

Sexo, raça e classe são marcadores que persistem como poderosas fontes de discriminação.

ALBERTINA DE OLIVEIRA COSTA

acosta@fcc.org.br 